\title{
Ultrasound-assisted preparation of electrospun carbon fiber/graphene electrodes for capacitive deionization: Importance and unique role of electrical conductivity
}

Gang Wang, Qiang Dong, Tingting Wu, Fei Zhan, Ming Zhou and Jieshan Qiu*

State Key Lab of Fine Chemicals, Liaoning Key Lab for Energy Materials and Chemical Engineering, PSUDUT Joint Center for Energy Research, Dalian University of Technology, Dalian 116024, China

\section{Abstract}

The desalination performance of capacitive deionization (CDI) technology is governed by electrode material properties, such as specific surface area, pore size and structure, surface functional groups, electrode geometry, and electrical conductivity. However, few studies have been conducted regarding the impact of the electrical conductivity of electrode materials on the desalination performance of CDI. In this study, monolithic composite web electrodes are fabricated. These electrodes are composed of reduced graphene oxide/activated carbon nanofiber with tuned conductivity by using an ultrasound-assisted electrospinning method. Freestanding monolithic carbon nanofiber webs function as a framework that prevents graphene sheets from restacking. The conductive graphene network helps quickly transfer electrons across the matrix while the ions are efficiently stored in the pores of the electrodes; as a result, a high electrosorption capacity for $\mathrm{NaCl}$ of $9.2 \mathrm{mg} / \mathrm{g}$ is achieved. The electrical conductivity of the electrodes is correlated with the ion removal efficiency of desalination. Results show that the

\footnotetext{
* Corresponding author. Tel/Fax: +86-411-84986080. E-mail address: jqiu@ dlut.edu.cn (J. Qiu)
} 
electrosorption capacity of desalination governed by the electric double-layer scheme can be improved by increasing the electrical conductivity of the electrodes. These findings may provide new insights into the design and fabrication of novel porous electrode materials and elucidate the importance and effects of electrode conductivity on CDI.

\section{Introduction}

The shortage in fresh water supply is a challenge faced by the world today[1]. An option to ensure freshwater availability is the desalination of seawater. Capacitive deionization (CDI) technology is a promising technology to desalinate water, especially low molar concentration streams, like brackish. In principle, a CDI cell consists of two porous carbon electrodes. Upon applying a voltage difference between two electrodes[2, 3] the ions are absorbed. The preferred materials as CDI electrodes are carbon materials because they own high internal surface area and porosity, and the CDI performance is governed by the properties of the carbon electrodes to a great degree[4-7].

In terms of morphological characteristics and textures, carbon electrodes can be classified into two categories: powder and monolith. Powder-like carbon materials, such as commercial activated carbon[8-14], carbon nanotubes (CNTs)[15-17], mesoporous carbon[18-21], and graphene[7, 22-24], have been evaluated as CDI electrodes for desalination; these materials should be fixed or bonded by adding a binder before use. The polymer binder likely increases the electrical resistance of the electrode and blocks some of the pores; subsequently, electrosorption capacity is reduced. As such, the carbon materials with free-binder monolithic structures, including carbon aerogel[6, 25, 26], CNTs/carbon fiber composite[27, 28], carbon nanotube 
sponge[29], and 3D graphene sponge[30-33], have intensively been investigated as CDI electrodes. These monolithic electrodes have shown a high electrosorption capacity, which is partly caused by the continuous monolithic structure with an enhanced electrical conductivity[34]. Considering these findings, we should develop ideal CDI electrode materials with high specific surface area (SSA), tuned porosity, and good conductivity[35]. With the advances in the fabrication of carbon monoliths with optimized SSA and porosity, electrosorption performance has been improved. Nevertheless, few studies have been conducted regarding the dependence of salt electrosorption capacity on the electrical conductivity of electrodes; as such, this parameter should be addressed in detail.

Electrospinning is a technology widely used to fabricate continuous nanofiber webs[36]. Researchers[37-39] developed freestanding thin webs consisting of porous activated carbon nanofibers (ACF) for both CDI and energy storage. The ACF webs exhibit good monolithic structure and high electrical conductivity; as such, these components show a high electrosorption capacity as electrode materials in CDI, as demonstrated in our previous work[40]. In addition, as an unique two dimensional structural material, reduced graphene oxide (RGO) has been theoretically and experimentally demonstrated to possess superior electrochemical performance. In particular, the theoretically superior conductivity, mechanical properties and excellent chemical stability make RGO an ideal filler candidate for adding the conductivity of the electrode composites. The present work aims to develop a versatile process to fabricate RGO/ACF composite electrodes and to improve the desalination capacity of the electrodes by tuning their electrical conductivity.

\section{Materials and Methods}

\subsection{Materials}




\subsubsection{Reduced graphene oxide (RGO) synthesis}

Graphene oxide (GO) was synthesized from natural graphite powder using a modified Hummers method[41]. Weighted GO was dispersed in $N, N$-dimethylformamide (DMF, Tianjin Fuyu Fine Chemical Co., Ltd.) for $1 \mathrm{~h}$ under ultrasonication $(40 \mathrm{kHz}, 100 \mathrm{~W})$; a dark brown suspension was obtained. Ethanediamine was then added to the GO suspension at $90{ }^{\circ} \mathrm{C}$ for 30 min; black RGO dispersion in DMF was produced and used for subsequent experiments.

\subsubsection{Preparation of RGO/ACF}

Polyacrylonitrile (PAN) $\left(\mathrm{M}_{\mathrm{w}}=150,000\right.$, Aldrich Chemical Co., USA) was added to the RGO dispersion in DMF and was stirred for $6 \mathrm{~h}$ at $60{ }^{\circ} \mathrm{C}$. A homogeneous RGO/PAN suspension was yielded for the preparation of RGO/PAN nanofibers by electrospinning at room temperature. The RGO/PAN solution was put into a $10-\mathrm{mL}$ glass syringe with a spinning needle. The detailed conditions for the electrospinning operation are as follows: the feeding rate of the RGO/PAN solution was $1.0 \mathrm{~mL} \mathrm{~h}^{-1}$, the applied voltage was $22 \mathrm{kV}$, the distance between the needle and the collector was $15 \mathrm{~cm}$, and the rotation rate of the collecting drum was $280 \mathrm{rpm}$. After electrospinning, the paper-like nanofibers were heated to $280{ }^{\circ} \mathrm{C}$ at a heating rate of $1{ }^{\circ} \mathrm{C} \mathrm{min}^{-1}$ in air for $2 \mathrm{~h}$. The temperature was then increased to $800{ }^{\circ} \mathrm{C}$ in $\mathrm{N}_{2}$ for $2 \mathrm{~h}$, and $\mathrm{N}_{2}$ was replaced with $\mathrm{CO}_{2}$ to activate the $\mathrm{RGO} / \mathrm{PAN}$ nanofibers at $800{ }^{\circ} \mathrm{C}$ for $1 \mathrm{~h}$. The composite was cooled back to room temperature in $\mathrm{N}_{2}$, yielding the RGO/ACF web. Pure ACF webs and RGO materials were also prepared under similar conditions mentioned above. The as-made RGO/ACF nanofiber webs with different RGO weight ratio to PAN at 1, 5, 10, and 15 wt $\%$ were denoted as RGO/ACF-X (X represents the weight ratio of RGO).

2.1.3 Preparation of RGO/ACF composite webs using the electrospinning coupled with ultrasonic spray process (S-RGO/ACF) 
The S-RGO/ACF composite webs were synthesized. First, the precursor PAN was dissolved in DMF under continuous stirring to obtain a polymer solution. GO dispersed in water at $2 \mathrm{mg}$ $\mathrm{mL}^{-1}$ was then prepared according to the reference[42]. Subsequently, the PAN-based fiber was created using a traditional electrospinning technique with a flow rate of $1 \mathrm{~mL} \mathrm{~min}^{-1}$, a tip to collector distance of $15 \mathrm{~cm}$, and a voltage of $22 \mathrm{kV}$. GO was incorporated through spraying using an ultrasonic atomizer (1.7 MHz, BSW-2A, Beirsi Co., China), as shown in Figure 1a. Then, the GO-embedded electrospun fibrous polymer webs were stabilized at $280{ }^{\circ} \mathrm{C}$ in air for $2 \mathrm{~h}$. The stabilized fibrous webs were then activated in $\mathrm{CO}_{2}$ at a rate of $5^{\circ} \mathrm{C} \min ^{-1}$ up to $800{ }^{\circ} \mathrm{C}$ to obtain S-RGO/ACF composite webs.

\subsection{Measurements}

The morphology of the samples was examined using a scanning electron microscope (SEM, JEOL S-4800). SSA was measured by nitrogen adsorption and was calculated by the BET equation (ASAP2020, Micromeritics, USA). Before the measurement was performed, the samples were degassed at $250{ }^{\circ} \mathrm{C}$ for $5 \mathrm{~h}$ under vacuum. The total pore volume was estimated from the amount of nitrogen adsorbed at $\mathrm{P} / \mathrm{P}_{0}=1$. Raman spectra of the samples were recorded on a LabRam-010 spectrometer with a resolution of $2 \mathrm{~cm}^{-1}$, a laser beam $\left(514.53 \mathrm{~nm}^{-1}\right)$ with an intensity of $1000 \mathrm{~mW}$, and a slit width of $3.5 \mathrm{~cm}^{-1}$. Schematic of four-probe method for measuring sheet resistance was found in Figure S1. The electrochemical performance of the electrodes was evaluated using cyclic voltammetry (CV). A three-electrode cell assembly was utilized with an $\mathrm{Ag} / \mathrm{AgCl}$ reference electrode, a Pt counter electrode, and a working electrode with an approximate diameter of $1 \mathrm{~cm}$ in $1 \mathrm{M}$ and $10 \mathrm{mM} \mathrm{NaCl}$ solution at room temperature. 
The potential was swept between $-0.5 \mathrm{~V}$ and $0.5 \mathrm{~V}$ at different scan rates. The gravimetric capacitance $(C, \mathrm{~F} / \mathrm{g})$, i.e., the specific capacitance per mass weight carbon electrode, is calculated by the equation below[43]:

$C=\frac{1}{m v \Delta V} \int_{V_{0}}^{V_{0}+\Delta V} I(V) d V$

where $m$ is the mass of the carbon electrode $(\mathrm{g}), v$ is the scan rate $(\mathrm{V} / \mathrm{s}), \Delta V$ is the sweep potential range during discharging $(\mathrm{V})$, and $I(V)$ is the corresponding current density $\left(\mathrm{A} \mathrm{g}^{-1}\right)$.

\subsection{Batch-mode electrosorption experiment}

The electrospun ACF and RGO/ACF series electrodes were evaluated as CDI electrodes, which were directly attached to the graphite current collectors to create a CDI cell. Experimental details of the CDI test system (Figure S2) can be found in the Supplementary Information (SI). The conductivity of the effluent can be converted into salt concentration according to a calibration curve. The adsorption capacity $(\Gamma, \mathrm{mg} / \mathrm{g})$ and charge efficiency $(\Lambda)$ can be calculated by equations (2) and (3), respectively:

$$
\begin{aligned}
& \Gamma=\frac{\left(C_{0}-C_{t}\right) \times V_{N a C l}}{m \times 10^{3}} \\
& \Lambda(\%)=\frac{m \times \Gamma \times F}{10^{3} \times M \times \int i \mathrm{~d} t} \times 100
\end{aligned}
$$

Where $C_{0}$ and $C_{\mathrm{t}}$ are the initial concentration $\left(\mathrm{mg} \mathrm{L}^{-1}\right)$ and the concentration at time $t(\mathrm{~min})$, respectively, $V_{\mathrm{NaCl}}$ is the volume flow rate of the solution $\left(\mathrm{mL} \min ^{-1}\right), M$ is the molar mass of sodium chloride $\left(58.5 \mathrm{~g} \mathrm{~mol}^{-1}\right), m$ is the total mass of both electrodes $(\mathrm{g}), i$ is the absolute value of current response during electrosorption (A) and $F$ is the Faraday constant $\left(96485 \mathrm{C} \mathrm{mol}^{-1}\right)$. 


\section{Results and Discussion}

To the best of our knowledge, studies have yet to be conducted to investigate the electrosorption desalination of electrodes composed of S-RGO/ACF composite webs fabricated via in situ ultrasonic atomization method (Figure 1a). The freestanding carbon nanofiber web acts as a framework of graphene and helps prevent the agglomeration or restacking of graphene. Another key role of this nanofiber web is to provide a high conductivity matrix for a rapid electron transfer and efficient ion transport to the pores. For comparison, the RGO/ACF composite web electrodes with different conductivities were prepared by direct electrospinning of mixed PAN and GO dispersions with various concentrations. Figure 1b shows the image of the surface of the S-RGO/ACF webs made by electrospinning at $22 \mathrm{kV}$. SEM analysis revealed that the average size of the GO nanosheets used in the present work is $2 \mu \mathrm{m}$. During the ultrasound-assisted electrospinning step, the GO nanosheets dispersed into the electrospun skeletons and attached to individual nanofiber surface, creating GO/polymer fiber composites. After the heat treatment, the PAN-based ACFs in the composites would act as bridges to connect the GO sheets. Compared with the RGO/ACF composites by direct electrospinning, the S$\mathrm{RGO} / \mathrm{ACF}$ composites have rougher structure where the conductive graphene wrapped up the nanofiber (Figure 1c); some graphene sheets are attached on the grid intervals between ACF to form a "plane-to-line" network (Figure 1d). The conducting network helps improve electron transfer in the matrix and improve ion transport to electrode pores. These electrodes are rich in well-connected tunnels for hydrated ions to easily move onto and off the surface of the composite electrode, which results in improved capacitive performance[33]. Pure ACF webs prepared using electrospinning without adding GO showed uniform fibers with diameters of 
several hundred nanometers (Figure 1e). Results demonstrated that the novel ultrasound-assisted electrospinning technique can effectively incorporate GO sheets into the RGO/ACF composites. This finding holds promise as a general approach to the large-scale fabrication of graphene/ACF composites with tuned structure and properties.

The $\mathrm{N}_{2}$ adsorption-desorption isotherms at $77 \mathrm{~K}$ of RGO, ACF, RGO/ACF-10, and SGRO/ACF samples are shown in Figure 2a. The ACF-containing samples and the major uptake occurs at relative pressure below 0.1. An almost horizontal plateau exists at higher relative pressure, indicating that the ACF-containing samples are porous with varying pore size distribution depending on the preparation conditions. In the case of the RGO sample, the $\mathrm{N}_{2}$ adsorption isotherm is type IV according to the IUPAC. The RGO sample has SSA of $53 \mathrm{~m}^{2} \mathrm{~g}^{-1}$, a total pore volume of $0.202 \mathrm{~cm}^{3} \mathrm{~g}^{-1}$, and an average pore diameter of $15.3 \mathrm{~nm}$. The pore size distributions of the RGO, ACF, RGO/ACF-10, and SGRO/ACF samples are shown in Figures $2 b$ and $2 c$. The pore structure parameters, the density, and the intensity ratio of $\mathrm{I}_{\mathrm{D}} / \mathrm{I}_{\mathrm{G}}$ of the Raman spectra band of other samples are shown in Table 1. The pore size distribution data shows that the mesopore volume of the as-made composites increase in comparison with that of ACF without graphene, indicative of mesopore formation caused by RGO incorporation. Electrode materials with wide pore width and mesoporous structure are favorable to relieve kinetic problems in the ion electrosorption process that are related to ion-transport resistance and the long diffusion distance from ion solution to the depths of pores.

The performance of the CDI technology is governed by a number of parameters, including electrical conductivity, total surface area, chemical composition, and pore structure of the electrode materials. Nevertheless, working out or pinpointing the effect of 
the electrical conductivity of the electrode materials remains a challenge. To date, no direct comparison between different electrode materials with similar specific surface area and chemical composition, yet varying electrical conductivity, can be found in the literature. Table 1 also shows the electrical conductivity of the electrode materials tested in the present work. Of these electrode materials, the S-RGO/ACF composite web created using the ultrasound-assisted electrospinning has the highest electrical conductivity of 42.6 $\mathrm{S} / \mathrm{m}$, in which the tight graft between the nanofibers and GO sheets is the key for a complex conductive network. The electrical conductivities of the RGO-containing ACF composite webs can be tuned by heat treatment caused by the elimination of the oxygencontaining groups and the reconstruction of $\mathrm{sp}^{2}$-hybridized chemical structure in the RGO sheets[44].

The CV analysis is a powerful tool to examine the capacitance and capacity of electrode materials for supercapacitors and CDI, respectively. Figure 3a shows the CV curves for ACF, RGO/ACF-10, and S-RGO/ACF samples at a scan rate of $2 \mathrm{mV} \mathrm{s}{ }^{-1}$. All CV curves have an approximately rectangular shape, indicative of a reversible electrosorption process in which no obvious redox peaks are observed. This observation implies that ions are adsorbed on the electrode surface via an electric double layer scheme caused by the Columbic interaction rather than the electrochemical reaction[45]. We also performed the $\mathrm{CV}$ test for $\mathrm{S}-\mathrm{RGO} / \mathrm{ACF}$ in $1 \mathrm{M}$ (Figure $3 \mathrm{~b}$ ) and $10 \mathrm{mM} \mathrm{NaCl}$ solution (Figure 3c) at various scan rate, respectively. Since the electrolyte in $10 \mathrm{mM} \mathrm{NaCl}$ solution is so dilute, the shape of the $\mathrm{CV}$ curves is not rectangular. However, the measured specific capacitance is closer to the real-life deionization situation compared with typical CV setup with a concentrated electrolyte. The specific capacitances of the 
electrode materials are $89 \mathrm{~F} \mathrm{~g}^{-1}$ for ACF, $100 \mathrm{~F} \mathrm{~g}^{-1}$ for RGO/ACF-10, and $111 \mathrm{~F} \mathrm{~g}^{-1}$ in 1 $\mathrm{M} \mathrm{NaCl}$ solution for S-RGO/ACF, respectively. The specific capacitance of the S$\mathrm{RGO} / \mathrm{ACF}$ electrode is higher than other two samples. The capacitance of the SRGO/ACF sample was further examined at higher scan rates (Figures 3d), showing a capacitance of $76 \mathrm{~F} \mathrm{~g} \mathrm{~g}^{-1}$ even at a high scan rate of $100 \mathrm{mV} \mathrm{S}^{-1}$. However, the ACF electrode without graphene lost most of the capacitance at a scan rate of $100 \mathrm{mV} \mathrm{S}^{-1}$ with only $36 \%$ capacitance retention. As expected, the capacitance in $10 \mathrm{mM} \mathrm{NaCl}$ solution dropped significantly when the scanning rate increases due to the large impedance of such dilute solution (Figure 3e). This finding implies that the S-RGO/ACF electrode has welldeveloped pore structure and better conductivity because the graphene conductive network allow efficient ion transfers at high scan rates[46]. The Nyquist plots of three samples are shown in Figure 3f. The plots show the most vertical line in a low-frequency region; the lowest equivalent series resistance value[47] was in the case of the SRGO/ACF electrode with the highest conductivity and the best capacitive behavior among the three samples tested.

Figure 4 shows the capacitive deionization results, or the desalination capacity of the composites with and without graphene. The S-RGO/ACF has an electrosorption capacity of $9.2 \mathrm{mg} / \mathrm{g}$ after half an hour, which is better than that of other samples. The electrodes are obtained from the same precursors by the same procedure under similar conditions. As can be seen in Table S2, the contents of different elements are almost similar. This finding implies that the as-made composite materials should exhibit a similar surface chemistry. 
Developed BET surface area is always desired for CDI desalination[48], however, with few exceptions there is no linear relationship between the BET surface area and capacity, mainly because the BET surface area is commonly measured by small $\mathrm{N}_{2}$ molecules. The small pores, which can be accessed by $\mathrm{N}_{2}$, may constrain the accessibility of ions in the solution. Linear plots of electrosorption capacity vs. BET surface area can be clearly observed in Figure S3, showing a bad fitting with a low correlation coefficient of 0.067. The result reveals that BET surface area has little effect on the capacity of carbon electrodes; thus, electrosorption capacity is significantly affected by other factors in our case. Figure 5 shows that the electrosorption capacity of these six electrodes increases gradually as the electrical conductivity of the electrodes increases. The data in detail can be found in Table S3. Linear plots of electrosorption capacity vs. electrical conductivity, as well as current efficiency vs. electrical conductivity can be clearly observed, showing a good fitting with high correlation coefficients of 0.74 and 0.85 , respectively. These results reveal that the electrical conductivity of carbon electrodes affects the current efficiency; thus, electrosorption capacity is increased or decreased. According to our published reports $[49,50]$, the ACF-based electrode has more better cycling data. Therefore, in this research, we only use the data to calculate electrosorption from the 1 st or 2 st cycle. In our case, the electrosorption capacities of ACF, RGO/ACF-10, and S-RGO/ACF are 4.7, 7.2, and $9.2 \mathrm{mg} \mathrm{g}^{-1}$, respectively. Obviously, the electrosorption capacity of the ACF composites for CDI can be greatly improved by the addition of RGO, as evidenced by the fact that electrodes with higher electrical conductivity perform desalination better. This observation leads one to conclude that carbon electrodes with high conductivity for CDI 
can facilitate electron transport in the electrode matrix and is also capable of increasing the current efficiency[51].

The cyclic operation and regeneration performance of S-RGO/ACF was further evaluated in a batch-mode setup with an initial conductivity of $300 \mathrm{mg} \mathrm{L}^{-1}$ of the $\mathrm{NaCl}$ solution at an applied charging voltage of $1.2 \mathrm{~V}$, which was removed in the desorption step during the cycles. The time for both adsorption and desorption was 60 min. Figure $5 b$ shows electrosorption-desorption in 2.5 cycles, along with the corresponding response current. No detectable degradation is observed after 2.5 cycles, indicating the stability of S$\mathrm{RGO} / \mathrm{ACF}$.

Figure 5c shows the schematic view of electrical double layer responsible for the electrosorption of ions. The freestanding webs of the ACF-based material with tuned pore structure and electrical conductivity, which are prepared by electrospinning, stabilization, carbonization, and activation, are essential as electrodes for CDI. The micropores lead to an enhanced electrical double-layer capacitance while the mesopores provide low-resistant pathways and channels for the ions through the porous fibers. The enhanced electrical conductivity of the composites by graphene addition (Figure 5d) is another vital factor in improving electrosorption capacity. The incorporated graphene may provide low-resistant pathways and channels for the ions to the porous fibers because of well-connected complex conductive network. 


\section{Conclusions}

Ultrasound-assisted electrospinning is a novel yet effective method to incorporate graphene in situ into the polymer fiber webs that have been transformed by heat treatment and activation to produce ACF webs with a monolithic continuous carbon skeleton structure and high conductivity. This kind of web-like graphene-containing ACF composites exhibit an improved electrosorption capacity as high as $9.2 \mathrm{mg} \mathrm{g}^{-1}$. The electrical conductivity of the electrode materials is linearly related to their electrosorption capacity for ions. We demonstrated that the ultrasound-assisted electrospinning process could be applied to fabricate composite electrodes composed of ACF and graphene with enhanced electrical conductivity and electrosorption capacity. This study may provide new insights into high-performance, energy-efficient, and cost-effective CDI. This study may also be used as a basis of the wide applications of functional ACF-based materials.

\section{Acknowledgements}

The authors acknowledge financial support from National Science Foundation of China (Nos. 21336001) and the Qaidam Salt Lake Chemical Joint Research Fund Project of NSFC and Qinghai Province State People's Government (No. U1507103). 


\section{References}

[1] Yermiyahu U, Tal A, Ben-Gal A, Bar-Tal A, Tarchitzky J, Lahav O. Rethinking desalinated water quality and agriculture. Science 2007; 318:920-921.

[2] Suss ME, Porada S, Sun X, Biesheuvel PM, Yoon J, Presser V. Water desalination via capacitive deionization: what is it and what can we expect from it? Energ Environ Sci. 2015;8(8):2296-2319.

[3] Dlugolecki P, Van der Wal A. Energy Recovery in Membrane Capacitive Deionization. Environ Sci Technol. 2013;47(9):4904-10.

[4] Porada S, Zhao R, Van der Wal A, Presser V, Biesheuvel PM. Review on the science and technology of water desalination by capacitive deionization. Prog Mater Sci. 2013;58(8):1388442.

[5] Gabelich CJ, Tran TD, Mel SIH. Electrosorption of Inorganic Salts from Aqueous Solution Using Carbon Aerogels. Environ Sci Technol. 2002;36:3010-9.

[6] Xu P, Drewes JE, Heil D, Wang G. Treatment of brackish produced water using carbon aerogel-based capacitive deionization technology. Water Res. 2008;42:2605-17.

[7] Li H, Lu T, Pan L, Zhang Y, Sun Z. Electrosorption behavior of graphene in $\mathrm{NaCl}$ solutions. J Mater Chem. 2009;19:6773-9. 
[8] Avraham E, Bouhadana Y, Soffer A, Aurbach D. Limitation of Charge Efficiency in Capacitive Deionization. I. On the Behavior of Single Activated Carbon. J Electrochem Soc. 2009;156:P95-P9.

[9] Choi J-H. Fabrication of a carbon electrode using activated carbon powder and application to the capacitive deionization process. Sep Purif Technol. 2010;70:362-6.

[10] Jeon SI, Park HR, Yeo JG, Yang S, Cho CH, Han MH, et al. Desalination via a new membrane capacitive deionization process utilizing flow-electrodes. Energ Environ Sci. 2013;6(5):1471-5.

[11] Suss ME, Biesheuvel PM, Baumann TF, Stadermann M, Santiago JG. In Situ Spatially and Temporally Resolved Measurements of Salt Concentration between Charging Porous Electrodes for Desalination by Capacitive Deionization. Environ Sci Technol. 2014;48(3):200815.

[12] Park B-H, Kim Y-J, Park J-S, Choi J. Capacitive deionization using a carbon electrode prepared with water-soluble poly(vinyl alcohol) binder. J Ind Eng Chem (Amsterdam, Neth). 2011;17:717-22.

[13] Gao X, Omosebi A, Landon J, Liu KL. Enhancement of charge efficiency for a capacitive deionization cell using carbon xerogel with Modified potential of zero charge. Electrochem Commun. 2014;39:22-5.

[14] Hatzell KB, Hatzell MC, Cook KM, Boota M, Housel GM, McBride A, et al. Effect of oxidation of carbon material on suspension electrodes for flow electrode capacitive deionization. Environ Sci Technol. 2015;49(5):3040-7. 
[15] Hou CH, Liu NL, Hsu HL, Den W. Development of multi-walled carbon

nanotube/poly(vinyl alcohol) composite as electrode for capacitive deionization. Sep Purif Technol. 2014;130:7-14.

[16] Liu Y, Pan LK, Xu XT, Lu T, Sun Z, Chua DHC. Enhanced desalination efficiency in modified membrane capacitive deionization by introducing ion-exchange polymers in carbon nanotubes electrodes. Electrochi Acta. 2014;130:619-24.

[17] Peng Z, Zhang D, Shi L, Yan T. High performance ordered mesoporous carbon/carbon nanotube composite electrodes for capacitive deionization. J Mater Chem. 2012;22:6603-12. [18] Mayes RT, Tsouris C, Kiggans JO, Jr., Mahurin SM, De PDW, Dai S. Hierarchical ordered mesoporous carbon from phloroglucinol-glyoxal and its application in capacitive deionization of brackish water. J Mater Chem. 2010;20:8674-8.

[19] Tsouris C, Mayes R, Kiggans J, Sharma K, Yiacoumi S, DePaoli D, et al. Mesoporous carbon for capacitive deionization of saline water. Environ Sci Technol. 2011;45:10243-9. [20] Li L, Zou L, Song H, Morris G. Ordered mesoporous carbons synthesized by a modified sol-gel process for electrosorptive removal of sodium chloride. Carbon. 2009;47:775-81. [21] Yang J, Zou LD. Recycle of calcium waste into mesoporous carbons as sustainable electrode materials for capacitive deionization. Micropor Mesopor Mat. 2014;183:91-8. [22] Li H, Zou L, Pan L, Sun Z. Novel Graphene-Like Electrodes for Capacitive Deionization. Environ Sci Technol. 2010;44:8692-7.

[23] Bai Y, Huang ZH, Yu XL, Kang FY. Graphene oxide-embedded porous carbon nanofiber webs by electrospinning for capacitive deionization. Colloid Surface A. 2014;444:153-8. 
[24] El-Deen AG, Choi JH, Kim CS, Khalil KA, Almajid AA, Barakat NAM. TiO2 nanorodintercalated reduced graphene oxide as high performance electrode material for membrane capacitive deionization. Desalination. 2015;361:53-64.

[25] Farmer JC, Bahowick SM, Harrar JE, Fix DV, Martinelli RE, Vu AK, et al. Electrosorption of Chromium Ions on Carbon Aerogel Electrodes as a Means of Remediating Ground Water. Energy \& Fuels. 1997;11(2):337-47.

[26] Jung H-H, Hwang S-W, Hyun S-H, Lee K-H, Kim G-T. Capacitive deionization characteristics of nanostructured carbon aerogel electrodes synthesized via ambient drying. Desalination. 2007;216:377-85.

[27] Liu Y, Li HB, Nie CY, Pan LK, Sun Z. Carbon nanotube and carbon nanofiber composite films grown on different graphite substrate for capacitive deionization. Desalin Water Treat. 2013;51(19-21):3988-94.

[28] Zhan Y, Nie C, Li H, Pan L, Sun Z. Enhancement of electrosorption capacity of activated carbon fibers by grafting with carbon nanofibers. Electrochi Acta. 2011;56(9):3164-9.

[29] Wang L, Wang M, Huang Z-H, Cui T, Gui X, Kang F, et al. Capacitive deionization of $\mathrm{NaCl}$ solutions using carbon nanotube sponge electrodes. J Mater Chem. 2011;21:18295-9. [30] Yang ZY, Jin LJ, Lu GQ, Xiao QQ, Zhang YX, Jing L, et al. Sponge-templated preparation of high surface area graphene with ultrahigh capacitive deionization performance. Adv Funct Mater. 2014;24(25):3917-25.

[31] Li Z, Song B, Wu ZK, Lin ZY, Yao YG, Moon KS, et al. 3D porous graphene with ultrahigh surface area for microscale capacitive deionization. Nano Energy. 2015;11:711-8. [32] Xu XT, Sun Z, Chua DHC, Pan LK. Novel nitrogen doped graphene sponge with ultrahigh capacitive deionization performance. Sci Rep. 2015;5:1-9. 
[33] Liu Y, Xu X, Lu T, Sun Z, Chua DHC, Pan L. Nitrogen-doped electrospun reduced graphene oxide-carbon nanofiber composite for capacitive deionization. Rsc Adv. 2015;5(43):34117-24.

[34] Inagaki M, Yang Y, Kang F. Carbon nanofibers prepared via electrospinning. Adv Mater. 2012;24(19):2547-66.

[35] Perreault F, Fonseca de Faria A, Elimelech M. Environmental applications of graphenebased nanomaterials. Chem Soc Rev. 2015;44(16):5861-5896.

[36] Zhang CL, Yu SH. Nanoparticles meet electrospinning: recent advances and future prospects. Chem Soc Rev. 2014;43(13):4423-48.

[37] Aravindan V, Sundaramurthy J, Suresh Kumar P, Lee YS, Ramakrishna S, Madhavi S. Electrospun nanofibers: a prospective electro-active material for constructing high performance Li-ion batteries. Chem Commun. 2015;51(12):2225-34.

[38] Jayaraman S, Aravindan V, Suresh Kumar P, Ling WC, Ramakrishna S, Madhavi S. Synthesis of porous LiMn2O4 hollow nanofibers by electrospinning with extraordinary lithium storage properties. Chem Commun. 2013;49(59):6677-9.

[39] Zhang Z, Shao C, Zou P, Zhang P, Zhang M, Mu J, et al. In situ assembly of welldispersed gold nanoparticles on electrospun silica nanotubes for catalytic reduction of 4nitrophenol. Chem Commun. 2011;47(13):3906-8.

[40] Dong Q, Wang G, Wu TT, Peng SP, Qiu JS. Enhancing capacitive deionization performance of electrospun activated carbon nanofibers by coupling with carbon nanotubes. $\mathrm{J}$ Colloid Interf Sci. 2015;446:373-8.

[41] Hummers WS, Offeman RE. Preparation Of Graphitic Oxide. Journal of the American Chemical Society. 1958;80(6):1339-1339. 
[42] Dong Q, Wang G, Qian BQ, Hu C, Wang YW, Qiu JS. Electrospun composites made of reduced graphene oxide and activated carbon nanofibers for capacitive deionization. Electrochim Acta. 2014;137:388-94.

[43] Wang G, Pan C, Wang L, Dong Q, Yu C, Zhao Z, et al. Activated carbon nanofiber webs made by electrospinning for capacitive deionization. Electrochim Acta. 2012;69:65-70.

[44] Lian M, Fan JC, Shi ZX, Zhang S, Li H, Yin J. Gelatin-assisted fabrication of graphenebased nacre with high strength, toughness, and electrical conductivity. Carbon. 2015;89:279-89.

[45] Kim T, Yoon J. CDI ragone plot as a functional tool to evaluate desalination performance in capacitive deionization. Rsc Adv. 2015;5(2):1456-61.

[46] Dong Q, Wang G, Hu H, Yang J, Qian BQ, Ling Z, et al. Ultrasound-assisted preparation of electrospun carbon nanofiber/graphene composite electrode for supercapacitors. J Power Sources. 2013;243:350-3.

[47] Garcia-Quismondo E, Santos C, Lado J, Palma J, Anderson MA. Optimizing the Energy Efficiency of Capacitive Deionization Reactors Working under Real-World Conditions. Environ Sci Technol. 2013;47(20):11866-72.

[48] Zhao R, Biesheuvel PM, Miedema H, Bruning H, Van der Wal A.. Charge Efficiency: A Functional Tool to Probe the Double-Layer Structure Inside of Porous Electrodes and Application in the Modeling of Capacitive Deionization. J Phys Chem Lett. 2010;1:205-10.

[49] Qian BQ, Wang G, Ling Z, Dong Q, Wu TT, Zhang X, et al. (2015) Sulfonated Graphene as Cation-Selective Coating: A New Strategy for High-Performance Membrane Capacitive Deionization. Adv Mater Interfaces, 2015;2:1500372 
[50] Wang G, Dong Q, Ling Z, Pan C, Yu C, Qiu JS, Hierarchical activated carbon nanofiber webs with tuned structure fabricated by electrospinning for capacitive deionization, J. Mater. Chem. 2012; 22: 21819.

[51] Zhao R, Satpradit O, Rijnaarts HHM, Biesheuvel PM, Van der Wal A. Optimization of salt adsorption rate in membrane capacitive deionization. Water Res. 2013;47(5):1941-52.

\section{Figure captions:}

Figure 1. (a) Schematic of the electrospinning process coupled with ultrasonic spraying; (b) top-view SEM image of the as-made S-RGO/ACF; (c) and (d) SEM images of the individual S-RGO/ACF fiber; (e) pristine ACF surface in the absence of graphene. 
Figure 2. (a) $\mathrm{N}_{2}$ adsorption-desorption isotherms at $77 \mathrm{~K}$ of $\mathrm{RGO}, \mathrm{ACF}, \mathrm{RGO} / \mathrm{ACF}-10$, and S-RGO/ACF webs. For clarity, the adsorbed volumes of S-GRO/ACF and RGO/ACF-10 samples were upward shifted at $50 \mathrm{~cm}^{3} \mathrm{~g}^{-1}$ and $100 \mathrm{~cm}^{3} \mathrm{~g}^{-1}$, respectively; (b) and (c) Pore size distribution of RGO, ACF, RGO/ACF-10, and S-RGO/ACF samples.

Figure 3. (a) $\mathrm{CV}$ curves of $\mathrm{ACF}, \mathrm{RGO} / \mathrm{ACF}-10$, and $\mathrm{S}-\mathrm{RGO} / \mathrm{ACF}$ samples in $1 \mathrm{M} \mathrm{NaCl}$ solution at a scan rate of $2 \mathrm{mV} \mathrm{s}^{-1}$; (b) $\mathrm{CV}$ curves of S-RGO/ACF in $1 \mathrm{M} \mathrm{NaCl}$ solution at various scan rates; (c) $\mathrm{CV}$ curves of $\mathrm{S}-\mathrm{RGO} / \mathrm{ACF} 10 \mathrm{mM} \mathrm{NaCl}$ solution at various scan rates; (d) gravimetric capacitance of three samples in $1 \mathrm{M} \mathrm{NaCl}$ solution at various scan rates; (e) gravimetric capacitance of three samples in $10 \mathrm{mM} \mathrm{NaCl}$ solution at various scan rates; (f) impedance comparison curves for three samples in $1 \mathrm{M} \mathrm{NaCl}$ solution, inset is the Warburg semicircles from the electrochemical impedance spectroscopy analysis.

Figure 4. Electrosorption capacities of the composites, ACF, and RGO as a function of time; these parameters were measured in a batch-mode setup with a feeding $\mathrm{NaCl}$ solution (100 $\mathrm{mg} \mathrm{L}^{-1}$ ) and at $1.2 \mathrm{~V}$ applied voltage.

Figure 5. (a) Electrosorption capacity of the electrodes with different conductivities $\left(\mathrm{C}_{0}=\right.$ $100 \mathrm{mg} \mathrm{L}^{-1}, \mathrm{~V}=1.2 \mathrm{~V}$ ); (b) Conductivity variation of the effluent and the corresponding current during 2.5 cycles, as measured in a batch-mode setup with a feeding $\mathrm{NaCl}$ solution (300 $\mathrm{mg} \mathrm{L}^{-1}$ ) and 1.2 V applied voltage. (c) Schematic view of electrical double layer responsible for the electrosorption of ions. (d) Schematic of complex conductive 
network formed by the incorporated graphene.

\section{Table caption:}

Table 1. Parameters of pore structure, intensity ratio of $\mathrm{I}_{\mathrm{D}} / \mathrm{I}_{\mathrm{G}}$ band of the Raman spectra, density and electrical conductivity of carbon electrodes. 


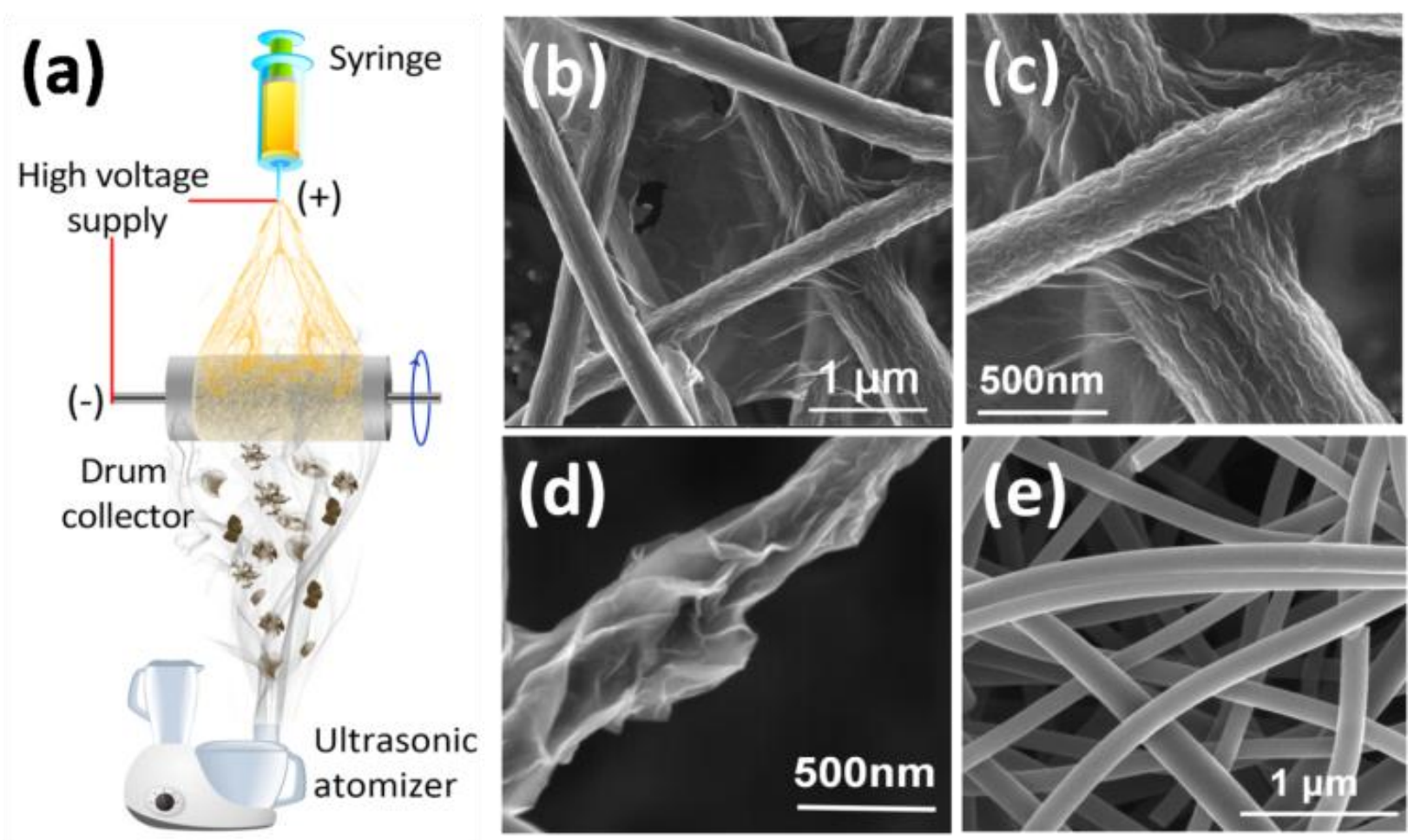

Figure 1. (a) Schematic of the electrospinning process coupled with ultrasonic spraying; (b) top-view SEM image of the as-made S-RGO/ACF; (c) and (d) SEM images of the individual S-RGO/ACF fiber; (e) pristine ACF surface in the absence of graphene. 

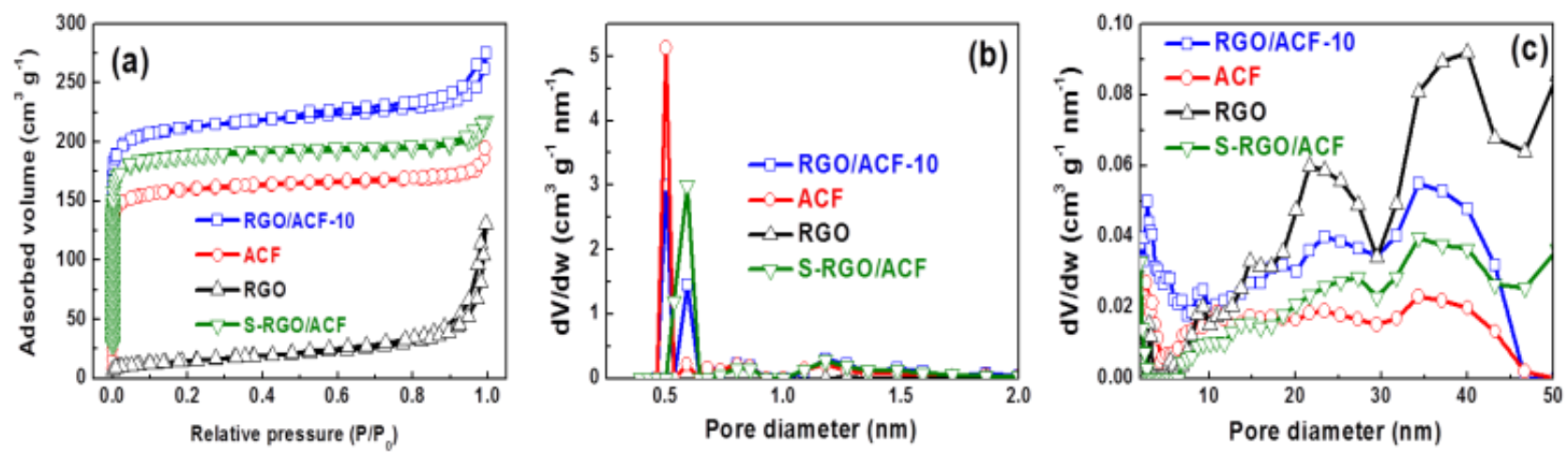

Figure 2. (a) $\mathrm{N}_{2}$ adsorption-desorption isotherms at $77 \mathrm{~K}$ of $\mathrm{RGO}, \mathrm{ACF}, \mathrm{RGO} / \mathrm{ACF}-10$, and S-RGO/ACF webs. For clarity, the adsorbed volumes of S-GRO/ACF and RGO/ACF-10 samples were upward shifted at $50 \mathrm{~cm}^{3} \mathrm{~g}^{-1}$ and $100 \mathrm{~cm}^{3} \mathrm{~g}^{-1}$, respectively; (b) and (c) Pore size distribution of RGO, ACF, RGO/ACF-10, and S-RGO/ACF samples. 

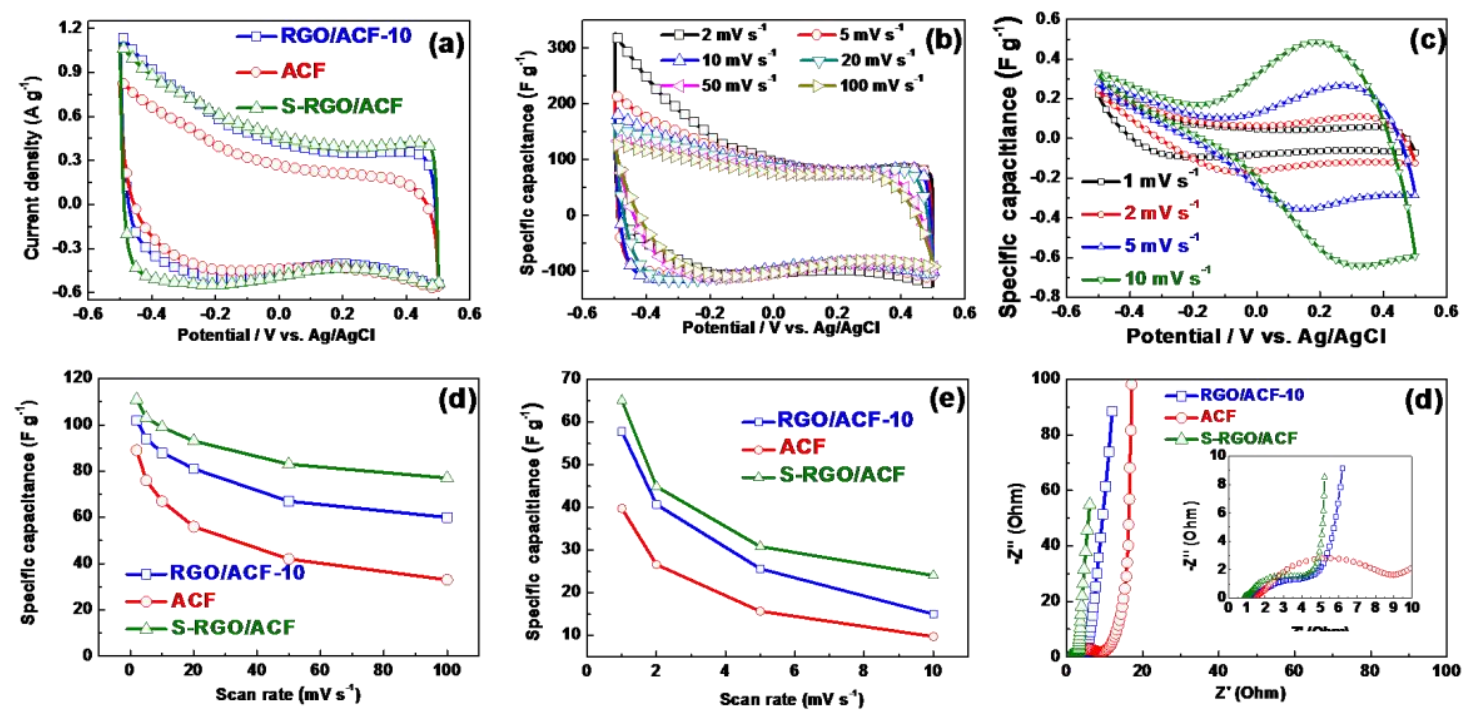

Figure 3. (a) $\mathrm{CV}$ curves of $\mathrm{ACF}, \mathrm{RGO} / \mathrm{ACF}-10$, and $\mathrm{S}-\mathrm{RGO} / \mathrm{ACF}$ samples in $1 \mathrm{M} \mathrm{NaCl}$ solution at a scan rate of $2 \mathrm{mV} \mathrm{s}^{-1}$; (b) $\mathrm{CV}$ curves of $\mathrm{S}-\mathrm{RGO} / \mathrm{ACF}$ in $1 \mathrm{M} \mathrm{NaCl}$ solution at various scan rates; (c) $\mathrm{CV}$ curves of S-RGO/ACF $10 \mathrm{mM} \mathrm{NaCl}$ solution at various scan rates; (d) gravimetric capacitance of three samples in $1 \mathrm{M} \mathrm{NaCl}$ solution at various scan rates; (e) gravimetric capacitance of three samples in $10 \mathrm{mM} \mathrm{NaCl}$ solution at various scan rates; (f) impedance comparison curves for three samples in $1 \mathrm{M} \mathrm{NaCl}$ solution, inset is the Warburg semicircles from the electrochemical impedance spectroscopy analysis. 


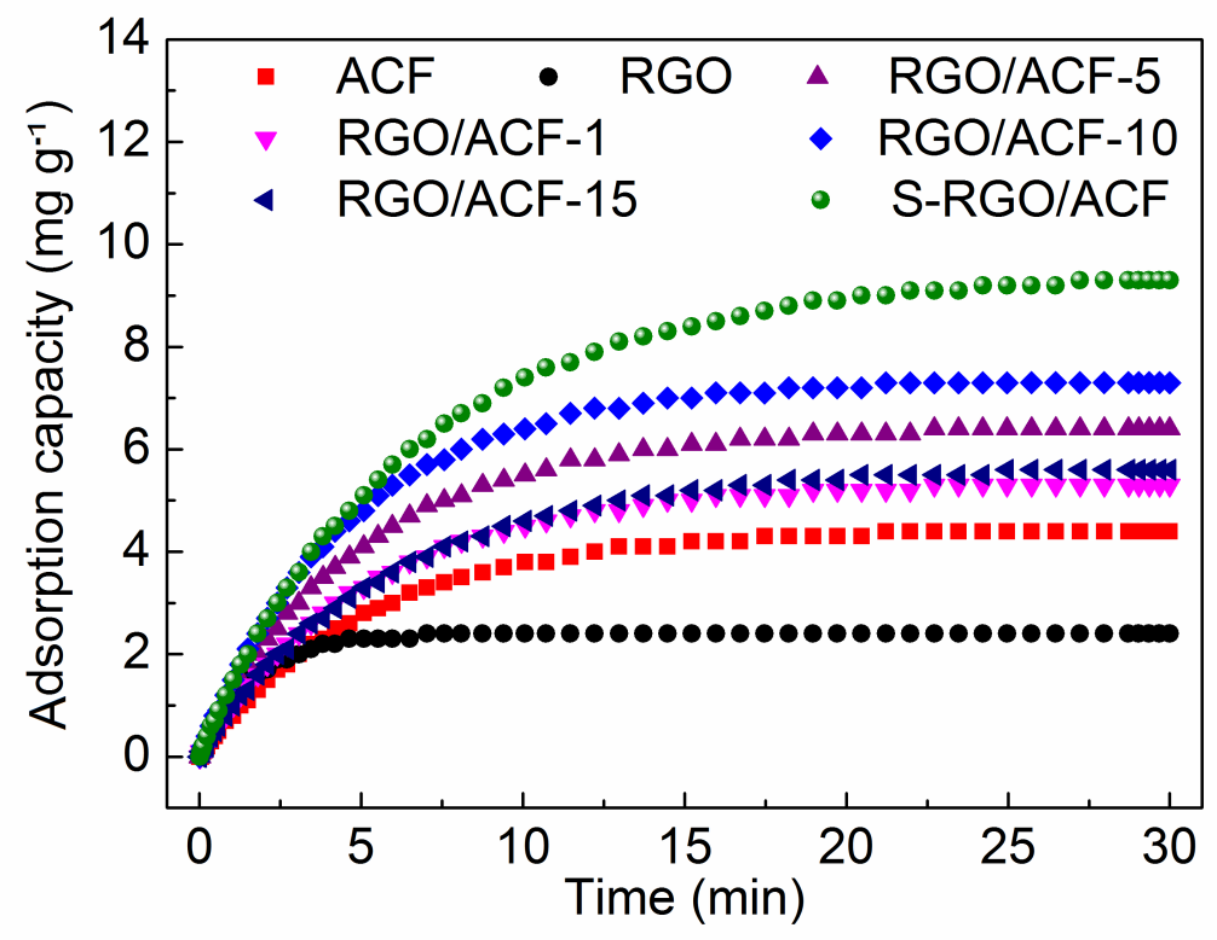

Figure 4. Electrosorption capacities of the composites, ACF, and RGO as a function of time; these parameters were measured in a batch-mode setup with a feeding $\mathrm{NaCl}$ solution $\left(100 \mathrm{mg} \mathrm{L}^{-1}\right)$ and at $1.2 \mathrm{~V}$ applied voltage. 

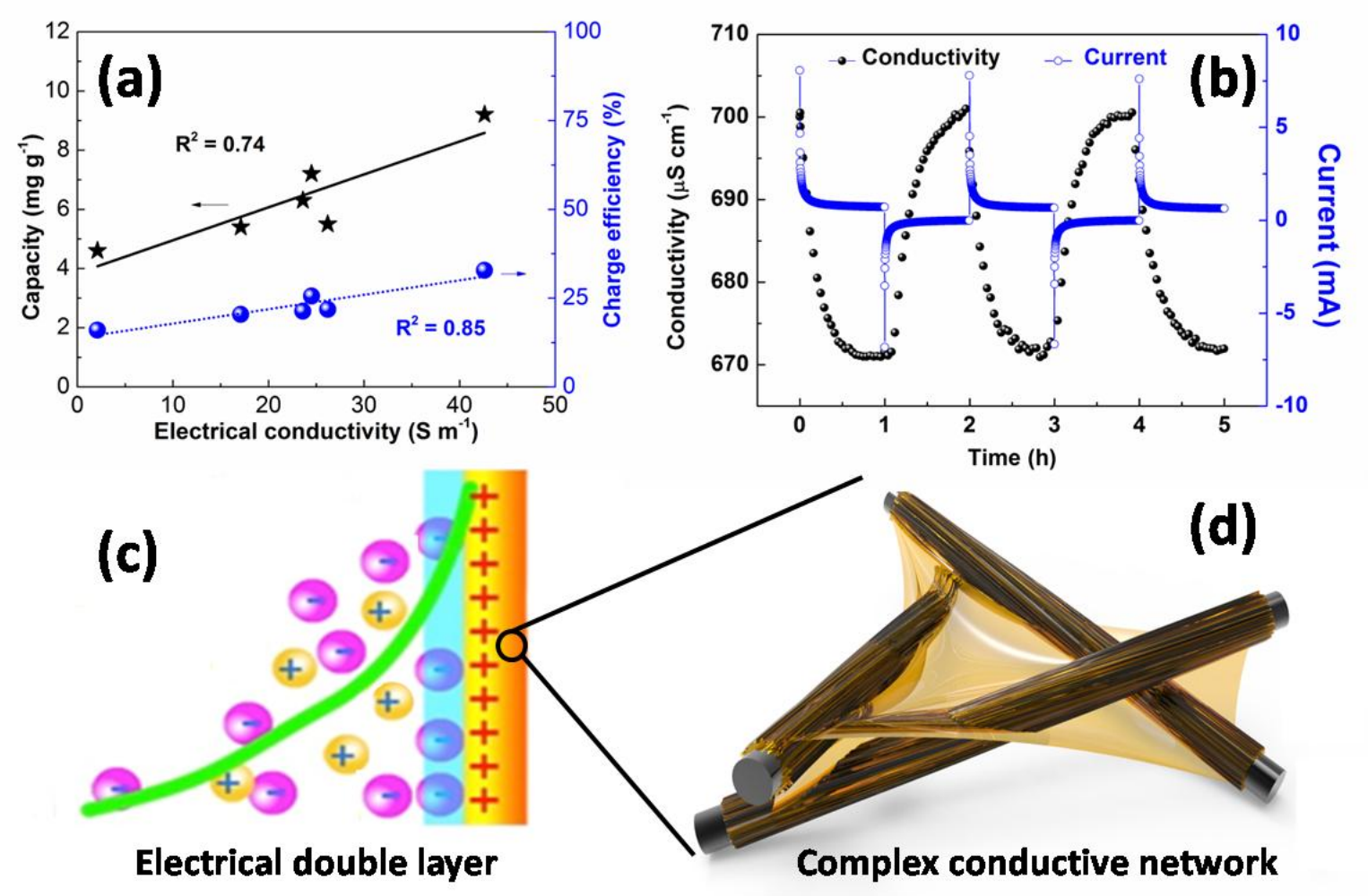

Figure 5. (a) Electrosorption capacity of the electrodes with different conductivities $\left(\mathrm{C}_{0}=\right.$ $100 \mathrm{mg} \mathrm{L}^{-1}, \mathrm{~V}=1.2 \mathrm{~V}$ ); (b) Conductivity variation of the effluent and the corresponding current during 2.5 cycles, as measured in a batch-mode setup with a feeding $\mathrm{NaCl}$ solution (300 $\mathrm{mg} \mathrm{L}^{-1}$ ) and 1.2 V applied voltage. (c) Schematic view of electrical double layer responsible for the electrosorption of ions. (d) Schematic of complex conductive network formed by the incorporated graphene. 
Table 1. Parameters of pore structure, intensity ratio of $\mathrm{I}_{\mathrm{D}} / \mathrm{I}_{\mathrm{G}}$ band of the Raman spectra, density and electrical conductivity of carbon electrodes.

\begin{tabular}{ccccccccc}
\hline Samples & $\mathrm{S}_{\mathrm{BET}}$ & $\mathrm{V}_{\text {total }}$ & $\mathrm{V}_{\text {mes }}$ & $\mathrm{V}_{\text {mic }}$ & $\mathrm{D}_{\text {ave }}$ & $\mathrm{I}_{\mathrm{D}} / \mathrm{I}_{\mathrm{G}}$ & Density & $\sigma$ \\
& $\mathrm{m}^{2} \mathrm{~g}^{-1}$ & $\mathrm{~cm}^{3} \mathrm{~g}^{-1}$ & $\mathrm{~cm}^{3} \mathrm{~g}^{-1}$ & $\mathrm{~cm}^{3} \mathrm{~g}^{-1}$ & $\mathrm{~nm}$ & & $\mathrm{~g} \mathrm{~cm}^{-3}$ & $\mathrm{~S} \mathrm{~m}^{-1}$ \\
\hline ACF & 630 & 0.301 & 0.077 & 0.215 & 1.9 & 3.18 & 0.93 & 2.1 \\
RGO & 53 & 0.202 & 0.206 & 0.001 & 15.3 & 1.47 & - & - \\
RGO/ACF-1 & 584 & 0.296 & 0.081 & 0.171 & 2.0 & 2.30 & 0.92 & 17.1 \\
RGO/ACF-5 & 612 & 0.344 & 0.082 & 0.233 & 2.2 & 2.11 & 0.88 & 23.6 \\
RGO/ACF-10 & 621 & 0.348 & 0.130 & 0.206 & 2.2 & 1.93 & 0.81 & 24.5 \\
RGO/ACF-15 & 456 & 0.256 & 0.090 & 0.154 & 2.2 & 1.92 & 0.85 & 26.2 \\
S-RGO/ACF & 649 & 0.292 & 0.090 & 0.209 & 2.0 & 1.93 & 0.77 & 42.6 \\
\hline
\end{tabular}




\section{Graphical Abstract:}

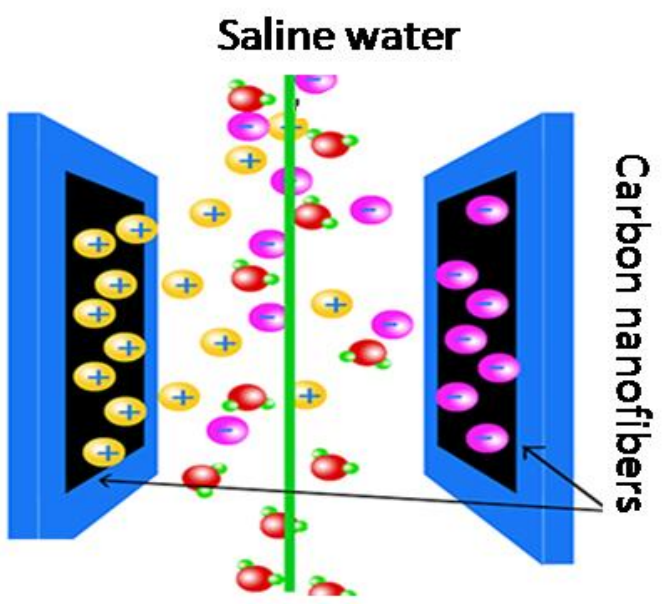

Purified water 